\title{
ANALISIS SEMIOTIKA PADA COVER NOVEL TRILOGI KARYA VIRA SAFITRI
}

\author{
Hanny Hafiar \\ Jimi Narotama M \\ Detta Rahmawan
}

Fakultas Ilmu komunikasi Universitas Padjadjaran

hannyhafiar@gmail.com; mahameruaji@gmail.com; dta.rr4@gmail.com

\begin{abstract}
A Novel's cover has an important role in attracting the attention of potential readers. Therefore the cover's illustration usually had been made as interesting as possible, in order to attract the readers. The readers tend to assume that the cover of a novel has a message that represents the content of the novel. Hence the more interesting the illustration is, the more interesting the contents of the novel. The trilogy novels by Vira Safitri, are young adult novels that goes into amore genre, which has the element of romance. Those three novels have peculiar illustration in their cover, which can be said quite successfully, represent the content of the novel. Based on that idea, this study tries to find out more about the symbols, the meaning of symbols and also how the symbols in Vira Safitri's novel's cover are able to build an impression in the minds of her readers. The method used in this study is semiotics by Charles S. Peirce, with the unit being analyzed is the cover's forms and the colors. The result shows that: symbols that are considered to have intentional meaning are the images of flowers, the drawing tools, and the colors. The image of the flower represent the countries which has been used as the main location in the novels, while the drawing tools represents the profession of one of the main characters, and the pastel color has been chosen to represent the scent of romance which is soft yet elegant. Thus it can be said that the illustration on the cover of Vira Safitri's trilogy novel has been able to describe the character's profession, location of the venue for the story, and also has been able to support the impression of an elegant, romantic, and a happy ending that characterizes a love story.
\end{abstract}

Keywords: Semiotics, Illustration, Novel, Symbols, Meaning

\begin{abstract}
Abstrak
Cover novel memiliki peran penting dalam menarik perhatian calon pembaca, oleh Karena itu ilustrasi pada novel dibuat semenarik mungkin karena pembaca cenderung beranggapan bahwa cover novel memiliki pesan yang mewakili isi novel, sehingga semakin menarik ilustrasi pada cover novel maka semakin menarik pula lah isi novel tersebut. Novel trilogi karya Vira Safitri, merupakan novel remaja dewasa yang masuk ke dalam genre amore, atau terdapat unsur percintaan. Ketiga novel tersebut memiliki kekhasan dalam ilustrasi covernya yang dapat dikatakan cukup berhasil mewakili isi novelnya tersebut. Berdasarkan pemikiran tersebut, maka tulisan ini dilakukan untuk mengetahui lebih lanjut mengenai simbol, makna simbol, serta bagaimana simbol dalam ilustrasi cover novel karya Vira Safitri mampu membangun kesan yang terbentuk di benak pembaca novelnya. Metode yang digunakan dalam kajian ini adalah semiotik dari Charles S. Peirce, dengan unit yang dianalisis berupa obyek gambar dan warna. Adapun hasil yang diperoleh antara lain: simbol yang dianggap memiliki
\end{abstract}


makna yang disengaja adalah obyek gambar bunga, gambar alat/property, dan warna. Adapun makna yang diwakili oleh gambar bunga yaitu perwakilan negara yang menjadi lokasi utama dalam novel, sedangkan gambar alat/properti mewakili makna profesi salah satu tokoh utama, dan warna pastel yang dipilih mewakili aroma percintaan yang lembut namun elegan. Dengan demikian maka dapat dikatakan bahwa ilustrasi pada cover novel trilogy karya Vira Safitri ini telah mampu menggambarkan profesi sang tokoh, lokasi tempat berlangsungnya kisah, serta telah mampu untuk mendukung kesan elegan, romantic, dan happy ending yang menjadi ciri khas novel kisah cinta.

Kata kunci: Semiotika, Ilustrasi, Novel, Simbol, Makna

\section{PENDAHULUAN}

Perkembangan dunia tulis menulis di Indonesia sedang mengalami kemajuan, di tengah maraknya isu buku bajakan, tak membuat penulis Indonesia kehilangan minatnya untuk selalu berkarya. Banyak karya penulis Indonesia yang menjadi best seller dengan salah satu indikatornya adalah mengalami proses cetak ulang untuk memenuhi permintaan pembaca yang belum berkesempatan memiliki buku tersebut. Pun begitu dengan novel karya Vira Safitri. Salah satu novelnya yang telah cetak ulang adalahNew York After The Rain. Artinya novel karyanya diminati oleh publik.

Ketertarikan pembaca akan karya novel Vira Safitri tak hanya dikarenakan kisahnya yang romantis, tokoh utamanya yang memiliki karakter menarik, penggambaran setting yang sangat ilustratif, gaya penulisan alur cerita yang mengalir tak tersendat, ataupun logika kisah pendukung yang ditulis dengan seksama saja, namun masih banyak factor lain, termasuk pengambilan ilustrasi untuk dijadikan cover novel.

Judul novel pertama dari trilogi novel bergenre amore yang dikaji berjudul Somewhere in Paris yang mengisahkan cerita cinta yang kompleks penuh flash back dari sang tokoh utama Cecilia Rodin-
Fernand Joseph Carlotti. Kisah dalam novel ini berbumbu amnesia pasca kecelakaan yang klasik, namun dibumbui dengan kejutan-kejutan yang menyenangkan. Untuk menggambarkan setting tempat yang berlokasi di kota Paris Perancis, ilustrasi cover novel tersebut mengambil menara Eiffel sebagai latar belakang seperti yang tergambar di bawah ini:

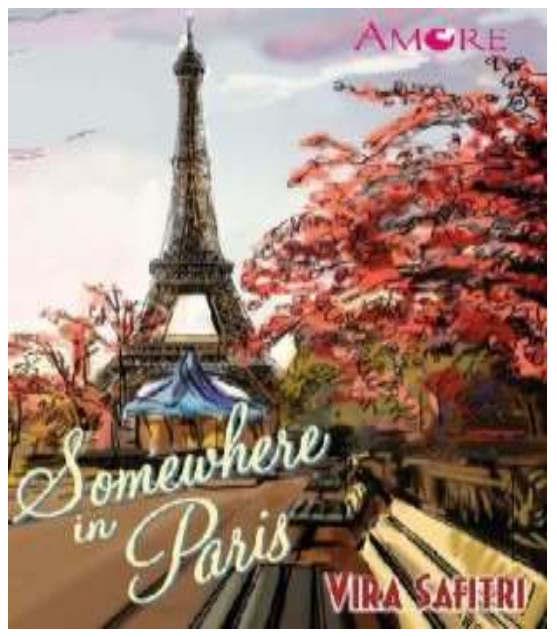

sumber:

http://www.goodreads.com/book/show/236268 98-somewhere-in-paris

Adapun novel kedua adalah New York After The Rain, kisah percintaannya melibatkan seorang penulis ternama, bernama Julia Milano yang menyembunyikan identitasnya dengan bekerja sebagai editor di salah satu penerbit dengan seorang sutradara muda yang introvert, Ethan Hall. Novel sebanyak 288 halaman yang diterbitkan pada bulan Mei 
2015 ini lah yang mengalami cetak ulang pertama. Selain faktor synopsisnya yang menarik, patut diamati bahwa cover novel ini lah yang menjadi patokan bagi pembuatan ilustrasi pada novel berikutnya.

Hal ini tergambar pada kesamaan pengambilan obyek bunga yang mewakili negara dan properti yang menunjukkan profesi sang tokoh utama. Sesuai dengan judul dan isinya, ilustrasi pada cover ini adalah bunga mawar dan mesin tik, seperti yang disajikan berikut ini:

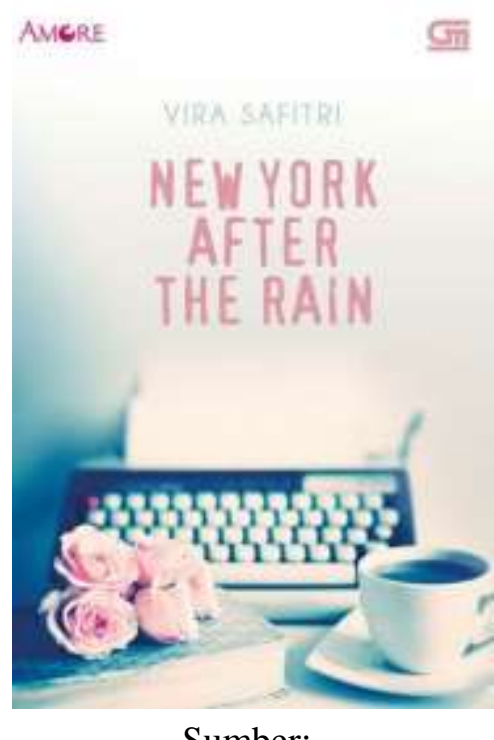

Sumber:

http://www.goodreads.com/book/show/25625

311-new-york-after-the-rain

Sedangkan novel ketiga dalam trilogi yang dikaji berjudul Remember Amsterdam. Sesuai dengan judulnya, novel ini mengambil setting tempat sebuah bandara di Kota Amsterdam sebagai lokasi yang dipilih penulis untuk mengawali kisah pertemuan antara Amy Maycott dan seorang pemain biola idola bernama Liam Sparks. Ada intrik dan kekerasan yang mewarnai novel ini, sekalipun kisah romantis masih sangat kental, untuk tetap menjaga tujuan bahwa novel tersebut bergenre amore.

Pada cover novel edisi tiga ini, ilustrasi yang dipilih mengikuti pola yang digunakan dalam novel kedua yaitu pengambilan obyek bunga khas negara dan biola untuk menggambarkan profesi salah satu tokoh utama, adapun ilustrasi cover novel ketiga ini dapat disajikan sebagai berikut:
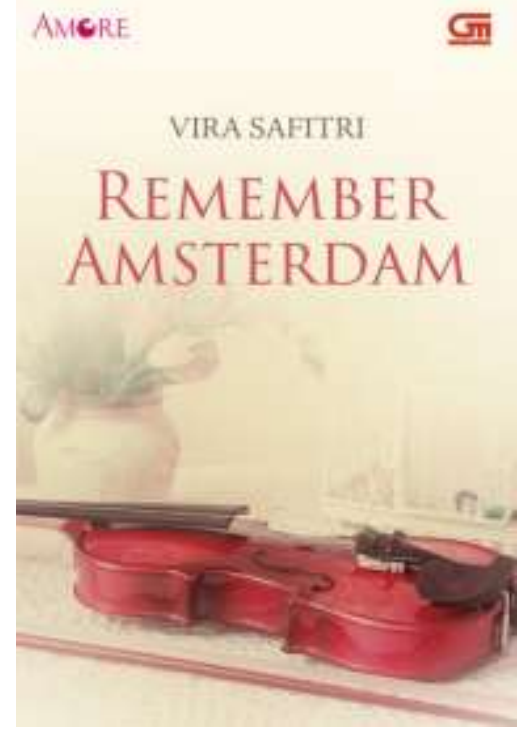

Sumber:

http://www.goodreads.com/book/show/29

097713-remember-amsterdam

Berdasarkan pemaparan tersebut, maka perlu kiranya ditelusuri penggunan symbol, makna simbol dan bagaimana simbol-simbol dalam ilustrasi cover tersebut mampu membangun sebuah gambaran mengenai isi cerita dari ketiga novel romantis tersebut dengan menggunakan analisis semiotika dari Charles Sanders Peirce.

Adapun alasan melakukan kajian terhadap cover novel ini, dikarenakan cover merupakan bagian dari karya desain komunikasi visual yang mempunyai tanda berbentuk verbal (bahasa) dan visual, serta merujuk bahwa teks desain komunikasi visual dan penyajian visualnya juga mengandung ikon terutama berfungsi dalam sistem non kebahasaan untuk mendukung pesan kebahasaan, maka pendekatan semiotika sebagai sebuah metode analisis tanda guna mengupas karya 
desain komunikasi visual layak diterapkan dan disikapi secara proaktif sesuai dengan konteksnya (Tinarbuko, 2003). Selain itu, Sebuah karya Desain Komunikasi Visual merupakan medium yang memiliki kemampuan sangat kuat dalam hal penyampaian sebuah pesan, mengubah persepsi serta membangun pencitraan (Wulandari, 2010)

\section{TINJAUAN PUSTAKA}

Kata semiotik digunakan oleh para leluhur Yunani sebagai the theory of signs (Krampen dkk, 1987: 1). Sign atau tanda adalah basis dari seluruh komunikasi (Littlejohn, 1996: 64). Manakala membahas mengenai semiotika, maka akan berkaitan dengan tanda. Segers menyatakan bahwa semiotika merupakan suatu upaya untuk meneliti semua bentuk komunikasi yang terjadi dengan tanda dan berdasarkan pada sistem tanda (Sobur, 27: 2009).

Semiotika merupakan sebuah ilmu atau metode analisis yang berusaha mengkaji dan membedah tanda yang ada dan berkembang dalam kehidupan manusia sehingga dapat diketahui maknanya. Semiotika menitikberatkan pada cara manusia memperesentasikan dunianya kepada dirinya sendiri maupun orang lain (Bopry, 2015).

Dalam semiotika, penerima dan pembaca tanda memiliki peran yang aktif dalam pemaknaan tanda. Penerima tanda atau komunikan turut berperan dalam menciptakan makna atas tanda yang diterimanya, pemaknaan ini tidak terlepas dari unsur pengalaman, sikap, dan emosi yang dimilikinya saat memberi makna pada suatu tanda (Merrell, 2001: 28-29).

Pada khasanah semiotika, Charles Sanders Peirce dikenal sebagai tokoh penting yang mengemukakan teori tentang tanda. Teori dari Peirce ini menjadi grand theory dalam semiotika (Deely, 1990: 90). Dalam teori tandanya Peirce mengungkapkan tiga konsep utama yang saling berkaitan, yaitu representament, object, dan interpretant.

Representamen digunakan oleh Peirce untuk merujuk pada suatu perceptible object. Untuk sebuah rujukan yang sama, ahli-ahli semiotika yang lain menggunakan istilah berbeda, seperti: simbol (versi Ogden \& Richard), sign vehicle (versi Morris), signifier (versi Saussure), dan expression (versi Hjelmslev) (Noth, 1995: 42).

Adapun object adalah unsur tanda yang dapat berbentuk benda, gagasan, ataupun apa saja yang diacu sebagai objek (Merrell, 2001: 28). Sedangkan interpretant adalah hasil interpretasi terhadap kenyataan yang ada dalam tanda, atau pemaknaan manusia terhadap tanda. Menurut peirce, representamen, objek dan interpretan saling berhubungan yang hubungannya dinyatakan sebagai: "a sign is representament with the mental interpretant" (Peirce, 1998: 273). Pada prinsipya semiotika Peirce merupakan kajian yang tak melepaskan unsur tanda dari pemahaman logika, hal ini merujuk pada pernyataan : Whereas the young Peirce strives to carve a place for logic within the part of semiotic he calls symbolistic, the older Peirce conceives of logic as semiotic; and this is to include grammar and rhetoric as well as logic in the narrow sense, or critic as Peirce most often calls the second branch of semiotic. (Bergman, 2007).

\section{METODE PENELITIAN}

Penelitian ini enggunakan metode semiotika Peirce dengan paradigma 
kontruktivis. Hal ini merujuk pada penyataan bahwa: studying semoitics can assist us to become more aware of reality as a construction and of the roles played by ourselves and others in constructing it (Chandler, 2994).

Bagi semiotik Peirce (1965, Vol. II: 242), tanda dapat dikenal pasti melalui proses semiosis dalam tiga kategori, yaitu: pertama representamen, kedua objek (object), dan ketiga (interpretant). Tanda merupakan hubungan segitiga (triadic) yang asli (genuine). Bagi Peirce, arti tanda yang sebenarnya ialah mengemukakan sesuatu, dan ia juga menyebutnya sebagai representamen (Panuti Sudjiman dan Aart Van Zoest, 1996: 7). Apa yang dikemukakan oleh tanda, apa yang diacunya, yang ditunjuknya, disebut oleh Peirce dalam bahasa Inggris object, dan juga digunakan kata designatum atau denotatum (Marlina, 1997).

Konsep yang terkandung dalam metode semiotik ala Peirce meliputi Firstness, secondness, dan thirdness (Noth, 1995: 41). Persinggungan antara konsep dalam teori semiotik Peirce yaitu representamen dengan firstness (otonom), secondness (disambungkan dengan realitas), dan thirdness (diakui secara konvensi) akan menghasilkan qualisigns, sinsign, legisign. Adapun persinggungan antara objek dengan Firstness, secondness, dan thirdness akan menghasilkan ikon, indeks dan simbol. Sedangkan persinggungan antara interpretan dengan Firstness, secondness, dan thirdness akan menghasilkan Rheme, dicent dan argument (Deledalle, 2000: 19).

\section{HASIL DAN PEMBAHASAN}

Analisis semiotika, tak hanya dapat dilakukan pada sebuah cover novel, namun juga dapat dilakukan pada isi karya sastra lain, seperti karya ilmiah yang menelaah isi novel karya sastrawan ternama yang menunjukkan hasil bahwa: kesemua novel yang diteliti menunjukkan indeks sebagai unsur semiotik yang paling besar dari segi kuantiti dalam plot (Sew, 2016).

$$
\text { Terdapat pendapat yang }
$$

menyatakan bahwa: Semiotics is concerned with meaning; how representation, in the broad sense (language, images, objects) generates meanings or the processes by which we comprehend or attribute meaning (Curtin, 2009). Oleh karena itu, kajian ini akan menekankan pada unsur simbol, makna dan bagaimana makna tersebut dikonstruksi.

\section{Simbol}

Simbol adalah penanda yang telah diakui secara konvensi, dan lazim digunakan dalam masyarakat. Simbol juga dapat dilahirkan dari suatu tradisi yang bersifat historis, namun simbol tidak tercipta dari sensasi ataupun relasi atas aksi dan reaksi, sebaliknya, simbol dipelajari melalui instruksi eksplisit (Merrell, 2001: 38). Sedangkan tanda, tak akan bermakna tanpa adanya pihak yang menandai, hal ini sejalan dengan pernyataan: The existence of signs does not come from signs per se. It is being adopted and assigned according to those people who give definition or explanation. There is not any signs can solely exist. On the other word, no any sign can exist with other signs incoherently.(Lin \& Lin, 2014)

Berdasarkan hasil analisis diketahui bahwa dalam ilustrasi cover novel Somewhere in Paris terdapat dua simbol utama yang diharapkan mampu menggambarkan isi novel yang dikemasnya, yaitu gambar dan warna. Adapun gambar diwakili oleh gambar menara Eiffel dan gambar bunga. Sedangkan warna diwakili oleh warna pink 
yang mendominasi bunga dan biru samar yang mendominasi warna langit. Seperti yang tergambar di bawah ini:

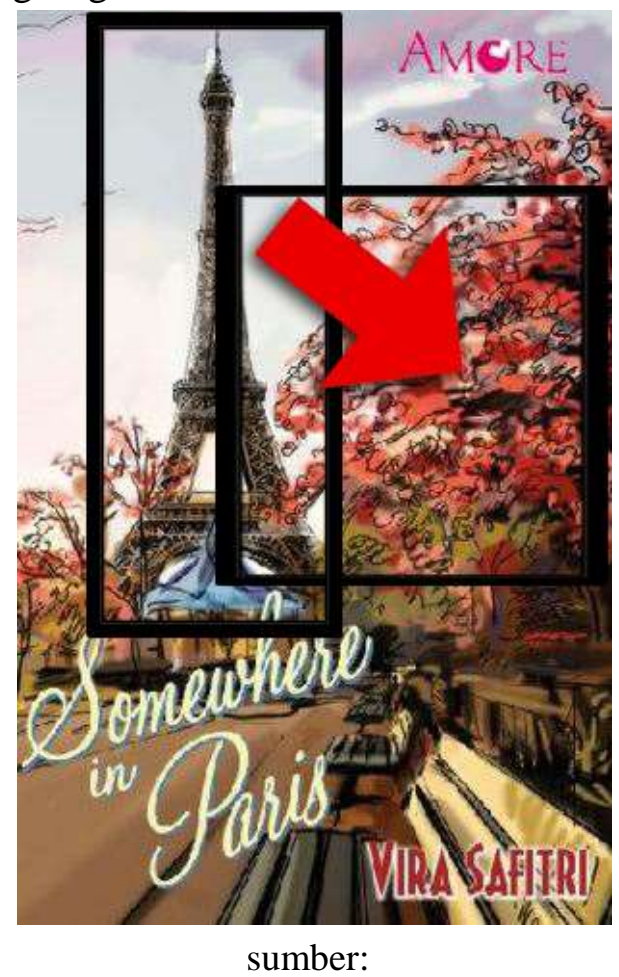

http://www.goodreads.com/book/show/23626 898-somewhere-in-paris (modifikasi penulis)

Sedangkan untuk edisi kedua yaitu New York After The Rain, terlihat adanya upaya mewakilkan sebuah nama negara kepada jenis bunga yang menjadi ciri khasnya. Bunga mawar (rose) merupakan bunga yang diklaim sebagai bunga yang menjadi ciri khas negara Amerika Serikat seperti yang dikutip dari www.kompasiana.com berikut ini:

"tahun 1986, Amerika mengumumkan bahwa emblem flora mereka adalah mawar. Dalam sebuah deklarasi resmi, Presiden Ronald Reagen menyatakan bahwa 'kita melihat mawar sebagai simbol kehidupan, cinta dan kesetiaan, kecantikan, dan keabaian, lebih dari bunga lain" (Kompasiana, 2016)

Adapun gambar lain yang terdapat pada ilustrasi cover adalah mesin tik dan buku yang menggambarkan profesi sang tokoh utama yaitu penulis. Selain itu terdapat simbol warna pink yang dipilih untuk bunga mawar dan nuansa di dinding yang menjadi latar belakang, sebagai efek tebaran dari warna merah yang dipakai untuk mewarnai huruf pada judul, sebagai berikut:

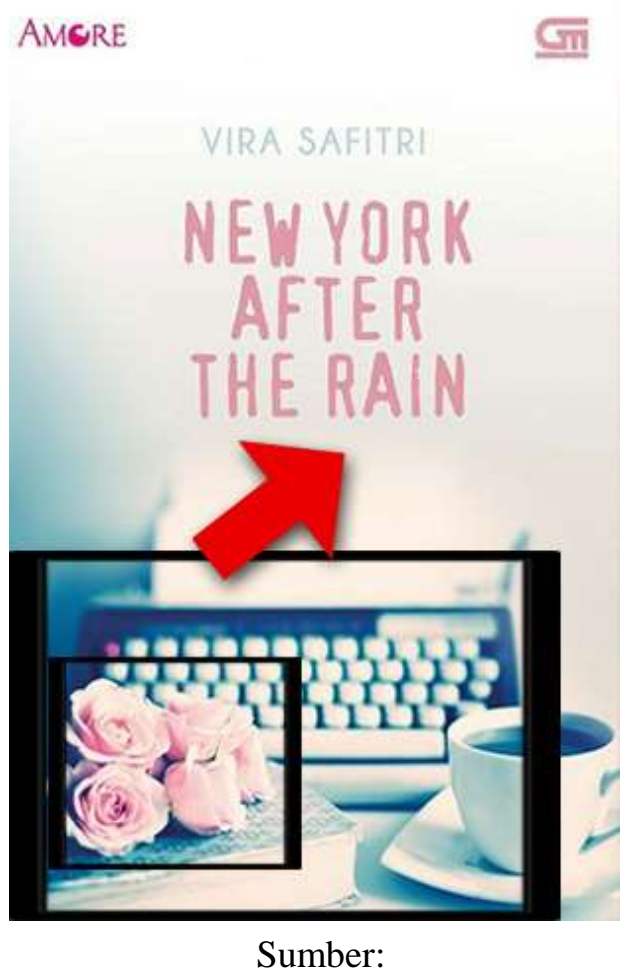

http://www.goodreads.com/book/show/256253 11-new-york-after-the-rain (modifikasi penulis) Pada novel ketiga yang diberi judul Remember Amsterdam, dapat diamati adanya keinginan untuk menggunakan simbol secara ajeg dalam novel-novel bergenre amore karya Vira Safitri ini. Hal ini terlihat dengan adanya kesamaan dalam penggunaan simbol bunga dan properti yang mewakili profesi tokoh utama. Maka dari itu ditampilkanlah gambar sebuah vas berisi bunga tulip dengan sebuah biola klasik di atas meja. Sedangkan tentang warna, ilustrasi dari novel ini tetap menampilkan warna pink yang berpendar dari vas bunga, Warna pink memiliki makna tersendiri secara psikologis yaitu: warna yang melambangkan cinta dan 
romantisme. Adapun ilustrasi pada cover dapat di lihat pada gambar berikut ini:

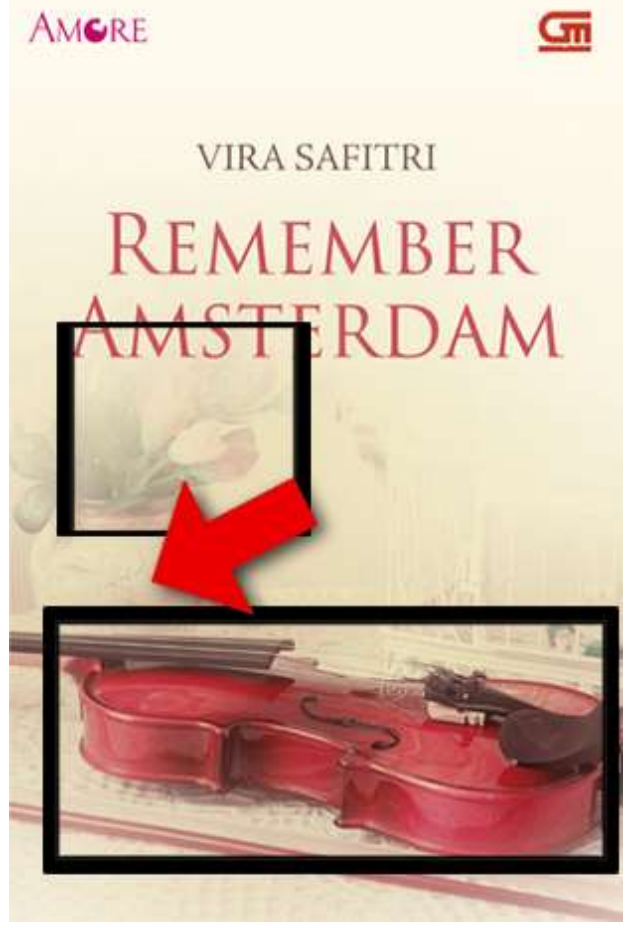

Sumber:

http://www.goodreads.com/book/show/290

97713-remember-amsterdam (modifikasi

$$
\text { penulis) }
$$

\section{Makna Simbol}

Simbol yang terdapat dalam ilustrasi pada cover novel yang pertama adalah bunga, menara Eiffel dan warna pink yang mendominasi nuansa warna pada cover. Ketiganya dimaksudkan untuk memberi gambaran bahwa isi novel tersebut bernuansa percintaan atau mengandung unsur romantisme.

Sedangkan Simbol yang terdapat dalam ilustrasi pada cover novel yang kedua adalah bunga, mesin tik, buku, dan warna pink yang muncul secara halus sebagai nuansa warna pada cover. Kehadiran obyek Bunga dan nuansa pink dimaksudkan untuk memberi gambaran bahwa isi novel tersebut mengandung kisah cinta yang manis. Dan bunga sebagai simbol yang mengandung pesan telah ada dan berkembang sejak zaman Victoria pada abad ke 18 (sumber: Tokobungaindo.com). Adapun gambar mesin tik dan buku adalah upaya illustrator untuk menggambarkan profesi salah satu tokoh utama yaitu sebagai penulis best seller.

Berikutnya, Simbol yang terdapat dalam ilustrasi pada cover novel yang ketiga adalah bunga, biola, dan warna pink yang berpendar dari vas bunga. Senada dengan maksud pada cover kedua, kehadiran obyek bunga dan nuansa pink dimaksudkan untuk memberi gambaran romantisme dari isi buku yang dikemasnya. Dan gambar obyek biola menggambarkan profesi salah satu tokoh utama, yaitu tokoh utama pria. Hal ini menarik, mengingat novel bergenre amore sesungguhnya cenderung menempatkan diri dari sudut pandang tokoh utama wanita.

\section{Konstruksi Ilustrasi Pada Cover Terhadap Isi}

Ilustrasi pda ketiga cover novel menunjukkan adanya upaya pembentukan makna untuk menimbulkan kesan di benak pembaca. Makna adalah hasil interpretasi, dan interpretasi merupakan proses kegiatan kreatif agar bisa mengungkapkan makna (Permana, 2015). Adapun pembentukan kesan dan makna dibangun melalui pemilihan obyek gambar dan warna. Kesan yang tampak ingin dibangun meliputi:

1. Kisah romantisme

2. Elegan

3. Berkelas

Kisah romantisme dibangun oleh penggunaan objek gambar bunga dan warna pink, adapun kesan elegan ditunjukkan oleh objek gambar profesi yang diwakili oleh gambar obyek properti/alat penunjang bagi profesi tertentu. Pada ketiga novel tersebut dikisahkan bahwa profesi pasangan tokoh utama pada novel pertama adalah guru dan dokter, pasangan tokoh utama pada novel kedua adalah penulis dan sutradara 
ternama, sedangkan pasangan tokoh utama pada novel ketiga adalah violist ternama dan pelukis.

Profesi-profesi yang dipilih oleh penulis untuk dijadikan profesi bagi tokoh utama merupakan profesi yang digambarkan menuntut adanya modal bakat, integritas, dan kekuatan ekonomi yang memadai. Hal ini pula lah yang merembet pada pembentukan kesan yang ketiga yaitu berkelas.

Pengambilan setting lokasi yang berada di luar negeri yaitu Perancis, Amerika dan Belanda menunjukkan adanya pemahaman dari penulis bahwa pembaca diharapkan mampu mencerna tentang konteks budaya, suasana yang khas, serta karakteristik individu di wilayah tersebut. Sebagai contoh, terdapat upaya penulis untuk menggambarkan suasana bandara pada novel ketiga kepada pembaca. Upaya ini akan sia-sia manakala pembaca mencerna kata demi kata tanpa gambaran negara Belanda dama sekali di benaknya.

\section{PENUTUP}

\section{Kesimpulan}

Terdapat beberapa simbol yang dimaksudkan oleh illustrator agar ilustrasi pada cover novel mampu menggambarkan isi novel dan menarik perhatian pembaca yang memiliki minat pada kisah-kisah romantisme yang berkelas dan elegan. Antara lain: simbol berupa gambar, yaitu: beberapa jenis bunga, menara Eiffel, Mesin Tik, Buku dan Biola. Adapun warna yang teridentifikasi selalu hadir dalam setiap ilustrasi cover adalah warna pink (merah muda).

Adapun makna yang terkndung dalam simbol-simbol tersebut meliputi gambar bunga dan menara Eifell serta warna pink yang menunjukkan bahwa novel tersebut berisi kisah romantisme; jenis bunga dan menara Eiffel untuk menunjukkan setting tempat yang dijadikan latar kisah dalam novel; serta properti atau alat untuk menunjukkan profesi salah satu tokoh utama.

Makna yang berhasil dikonstruksi oleh ilustrasi pada cover terhadap isi novel adalah bahwa isi setiap novel merupakan kisah romantisme yang menyajikan tokoh yang memiliki karakter elegan dan berkelas, sehingga novel ini secara tidak langsung menyasar segmen pembaca penyuka kisah romantis yang happy ending dengan latar belakang status social menengah ke atas.

\section{Saran}

Apabila novel ini dimaksudkan untuk dijadikan suatu karya novel yang berkesinambungan maka diharapkan ilustrasi pada cover novel pun memiliki pola ilustrasi yang ajeg dan konsisten. Konsistensi ilustrasi pada cover mulai terlihat sejak novel kedua.

Sebaiknya apabila edisi pertama direncanakan untuk cerat ulang, maka tidak ada salahnya jika dalam ilustrasi cover pada edisi cetak ulang dapat dimodifikasi dengan menambahkan kejelasan pada jenis bunga yang mewakili negara Perancis dan juga profesi salah satu tokohnya yaitu guru ataupun dokter, melalui tampilan profesi yang dapat diletakkan di atas bangku panjang yang sudah ada dalam ilustrasi sebelumnya. Apabila akan dilanjutkan novel edisi berikutnya, jenis huruf dan penetapan posisi judul dapat menggunakan pola yang sudah dipakai pada edisi dua dan tiga dengan memilih huruf yang lebih kental unsur romantismenya.

\section{DAFTAR PUSTAKA}

Bergman, M. (2007). The secret of 
rendering signs effective: the import of

C. S. Peirce's semiotic rhetoric. The Public Journal of Semiotics, 1/2, 2-11.

Retrieved from http://pjos.org/issues/pjos-3-1.pdf

Bopry, J. (2015). Semiotics, Epistemology and Inquiry.Journal diakses melalui

www.und.edudept/ehd/journal/bo pry.html

Chandler, Daniel. (1994). Semiotics for Beginner. London: Routledge

Curtin, B. (2009). Semiotics and Visual Representation Semiotics and Visual Representation.

Deely, J. (1990). Basics of Semiotics. Bloomington. Indiana: University Press

Deledalle, G. (2000). Charles S. Peirce's Philosophy of Signs. Bloomington: Indiana University Press

Krampen, M., Oehler, K., Posner, R., Sebeok, T., Uexkull, T. (1987). Classics of Semiotics. Boston, MA: Springer.

Lin, C., \& Lin, T. (2014). Using Triadic Semiotics in Storytelling. Art and Designing Review, (November), 7884.

https://doi.org/http://dx.doi.org/10.42 36/adr.2014.24010

Marlina, T. I. (1997). Teori Semiotik Peirce dan Morris: Suatu Pengenalan. National University of Malaysia.

Merrell, F. (2001). Charles Sander Peirce's Concept of the Sign. London: Routledge

Noth, W. (1995). Handbook of Semiotics. Blomington: Indiana University Press

Peirce, C., Houser, N., Eller, J. Et. All (1998). The Essential Peirce.
Bloomington: Indiana University Press

Permana, R. S. M. (2015). Makna Tri Tangtu Di Buana Yang Mengandung Aspek Komunikasi Politik Dalam Fragmen Carita Parahyangan. Jurnal Kajian Komunikasi, Volume 3,(23), 173-191.

Sew, J. W. (2016). Analisis Kajian Sastera : Semiotik dalam Novel Anwar Ridhwan. Akademika, 86(2), 53-63.

Sobur, Alex (2009). Analisis Teks Media. Bandung: Remaja Rosdakarya

Tinarbuko, S. (2003). Semiotika Analisis Tanda Pada Karya Desain Komunikasi Visual. Nirmana, 5(1), 31-47.

Wulandari, S. (2010). Bedah Logo Autocillin Menggunakan Teori Semiotika. Humaniora, 1(9), 478488. 